\title{
NUMERICAL INVESTIGATIONS ON THE RESIDUAL CAPACITY AND ECONOMIC LOSSES OF EARTHQUAKE-DAMAGED REINFORCED CONCRETE WALL STRUCTURES
}

\author{
Cristiana Ceccarelli $^{1}$, Simona Bianchi ${ }^{1}$, Livio Pedone ${ }^{1}$, Stefano Pampanin ${ }^{1}$ \\ ${ }^{1}$ Sapienza University of Rome, \\ Department of Structural and Geotechnical Engineering, Via Eudossiana 18, 00184, Rome, Italy, \\ ceccarelli.1530827@studenti.uniroma1.it, simona.bianchi@uniroma1.it, \\ livio.pedone@uniroma1.it, stefano.pampanin@uniroma1.it
}

\begin{abstract}
The substantial damage to Reinforced Concrete $(R C)$ structural walls observed from postearthquake reconnaissance has prompted the attention on the need for improved code-based design provisions for these structural elements as well as for detailed investigations on their residual capacity, typically neglected in the retrofit/repair evaluation. Although several research works and international guidelines focusing on the seismic performance of damaged structural walls are available from a state-of-the-art review, a specific methodology to evaluate the earthquake-related damage to structural walls is still missing in literature. Therefore, this research work investigates the seismic residual capacity of $R C$ walls through parametric numerical analyses, aiming to provide indications on the assessment methodology to be used in practical applications. The numerical investigation is initially carried out by implementing Finite Element Modelling of RC walls with different mechanical properties and expected failure mechanisms. This allows to evaluate and collect stiffness/strength reduction coefficients to be adopted for different post-earthquake damage conditions. Then, the influence of residual capacity on the economic seismic losses of wall structures is investigated and discussed. Specifically, a multi-story case-study RC building is selected, and pre- and post-earthquake loss assessments are carried out considering alternative wall typologies and damage levels. Analytical-based nonlinear analyses highlight that the loss of stiffness and strength can lead to increasingly higher economic losses depending on the damage level of the structural wall. Moreover, substantial economic losses can be estimated if residual capacity is taken into account even at low-intensity seismic levels. Therefore, such methodology could provide valuable information to support decisions on the post-earthquake repair/retrofit/demolition.
\end{abstract}

Keywords: Residual Capacity, Seismic Assessment, Reinforced Concrete, Wall Structures, Repair Costs. 


\section{INTRODUCTION}

The recent seismic events in seismic-prone countries have further highlighted the controversial issues related to the rehabilitation of earthquake-damaged buildings. On one hand, rapid post-earthquake surveys are needed for the evaluation of the safety level of damaged buildings and their possible re-occupancy [1]. On the other hand, a detailed assessment of the seismic residual capacity of damaged buildings, including loss investigations, is critical to support the decision-making process of repair vs. demolition and guide in the selection/design and implementation of appropriate techniques able to 'restore' the building to its undamaged conditions. Moreover, the crucial need to gain a better understanding of the residual capacity of earthquake-damaged buildings refers to both existing and new structures. In fact, according to the "Capacity Design" philosophy, even modern buildings are often affected by extensive structural damage after a major earthquake, as observed in Kam et al. [2] during the Canterbury Earthquake Sequence 2010-2011.

Focusing on Reinforced Concrete (RC) structural walls, widely used as primary lateralforce resisting systems in earthquake-resistant structures, the substantial damage to these components observed from post-earthquake reconnaissance (2010 Darfield and 2011 Lyttleton in New Zealand [2]; 2010 Chile [3]; Figure 1) has prompted the attention on the need for improved code-based design provisions for these structural elements as well as for detailed investigations on their residual capacity, typically neglected in the retrofit/repair evaluation.

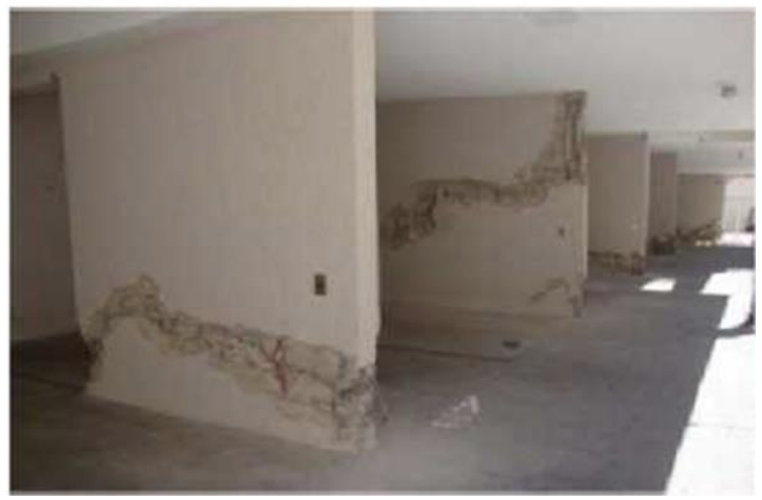

a)

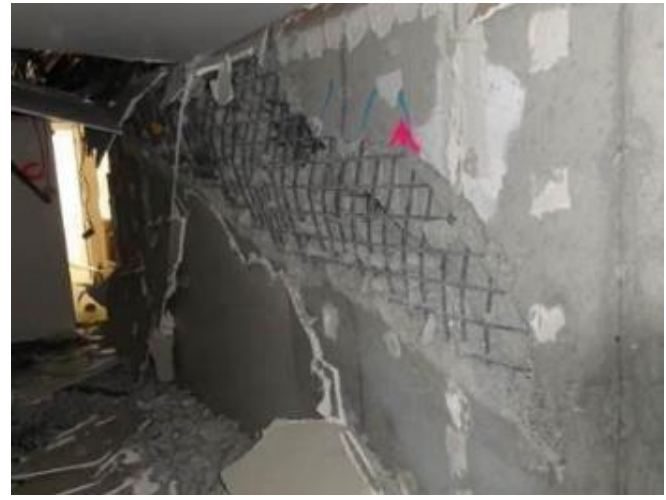

b)

Figure 1: Observed damage to RC structural walls in a) the 2010 Chile earthquake [3] and b) the 2011 Lyttleton earthquake, New Zealand [2].

Despite research works and international guidelines focusing on the seismic performance of damaged structural walls are available in literature (e.g. FEMA 306 [4]; JBDPA Guideline [5]), a specific methodology to evaluate the earthquake-related damage to structural walls as well as the consequent loss of stiffness/strength affecting the component capacity is still missing. Following this goal, this paper aims to investigate the seismic residual capacity of RC walls through numerical modelling, providing indications on both the methodology and the stiffness/strength reduction coefficients to be adopted for different post-earthquake damage levels. A parametric analysis is thus developed to study the residual capacity of RC walls with different mechanical properties and expected failure mechanisms (flexural, flexure-shear, shear). The structural walls are analyzed adopting a refined FEM modelling approach, based on the modified compression field theory, using the structural software VecTor2 (Vecchio [6]). Firstly, the seismic behavior of the RC walls under reversed-cyclic loads is investigated to simulate the achievement of specific damage states, assessing residual cracks and residual 
displacements at each damage level. Then, a unidirectional monotonic lateral load is applied to the damaged wall to evaluate the force-displacement capacity curve for each configuration. Hence, according to the FEMA 306 approach, stiffness and strength reduction coefficients, namely $\lambda_{\mathrm{k}}$ and $\lambda_{\mathrm{Q}}$ respectively (as shown in Figure 2), are derived by comparing the pre- and post- earthquake force-displacement curves for each damage state and wall configuration. Lastly, the influence of residual capacity on the estimation of the economic seismic losses of wall structures is also investigated and discussed. Specifically, a RC case-study building is selected, and loss assessments are implemented considering different wall typologies and damage levels. For each configuration, the economic losses are computed in terms of both Expected Annual Losses (EAL) and Probable Maximum Losses (PML) to highlight the importance of including residual capacity considerations when implementing economic analyses.

\section{EVALUATION OF RESIDUAL CAPACITY}

In the past decades, a substantial research effort has been dedicated at international level to gain a better understanding of the post-earthquake residual capacity of buildings. In 1994 Holmes [7] discussed the critical need for improved seismic assessment accounting for the actual lateral load of buildings and considering different damaged levels. Following this research line, two main guidelines were developed: 1) FEMA 306 [4] in the United States, and 2) JBDPA Guideline [5] in Japan (described in English in Nakano et al. [8]; overview available in Maeda et al. [1]). Both documents propose a conceptually similar approach, based on the definition of capacity reduction factors for structural members to simulate the achievement of a specific damage state. In FEMA 306 a modification of plastic hinges' response is proposed for damaged elements, based on stiffness, strength and ductility reduction coefficients, namely $\lambda_{\mathrm{k}}, \lambda_{\mathrm{Q}}$ and $\lambda_{\mathrm{D}}$ (Figure $2 \mathrm{a}$ ). In the JBDPA Guideline a single capacity reduction factor for structural members, i.e. $\eta$, defined as the ratio between residual energy dissipation capacity and original energy dissipation capacity is adopted (Figure $2 b$ ).

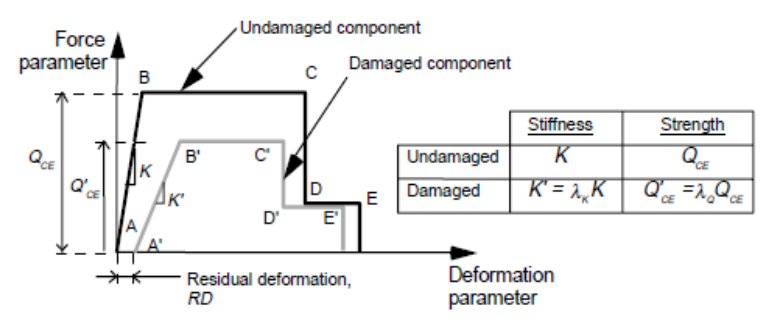

a)

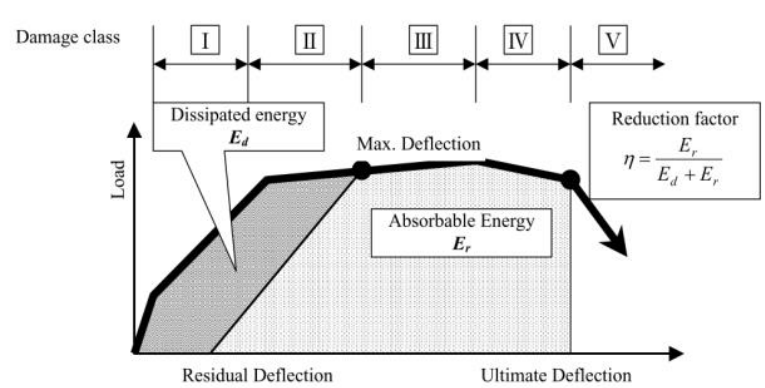

b)

Figure 2: a) Stiffness, strength and residual displacement reduction coefficients in FEMA 306 [4]; b) capacity reduction factor for structural members in JBDPA Guideline [5].

Furthermore, FEMA 307 [9] reports background and theoretical information as well as an example of application of the FEMA 306 procedure. According to FEMA 306 (whose procedure is adopted within this research work), the most reliable approach to determine $\lambda$ reduction factors would consist of performing experimental investigations on two identical specimens for each structural component. One specimen would represent the component in its pre-earthquake condition, while the other specimen would represent the component in its post-earthquake condition (i.e., earthquake-damaged). Therefore, the reduction factor values would be derived by comparing the force-displacement capacity curves of the two specimens. However, FEMA 307 highlights that at the date of the document, no such test campaigns on $\mathrm{RC}$ walls were available in literature to calculate the $\lambda$ factors. In the absence of this type of 
tests, an alternative approach was adopted, based on individual cyclic-static tests. According to this approach, the change in force-displacement response from cycle to cycle is examined as the displacement increases. As reported in FEMA 307, firstly the component type and behavior mode (e.g., flexural, shear, etc.) are defined according to the selected test. The critical damage states (e.g., spalling, cracking, etc.) are observed during the load-displacement history of the test and are correlated with the displacement ductility achieved by the component. Then, by comparing the initial and subsequent cycles, $\lambda$ factors are derived. Finally, both the critical damage indicators and the associated reduction factors are discretized into six damage severity levels (from "None" to "Extreme"). An example of FEMA 306 component damage classification is reported in Figure $3 \mathrm{a}$ for an isolated wall with ductile flexural behavior and "Insignificant" damage level. It is worth noting that, even for "Insignificant" damage level, stiffness reduction occurs, since the component stiffness is most sensitive to damage, as shown in Figure $3 b$.

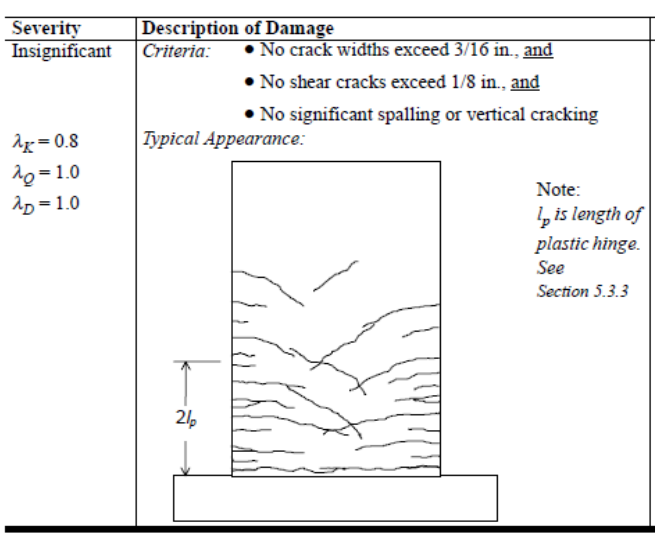

a)

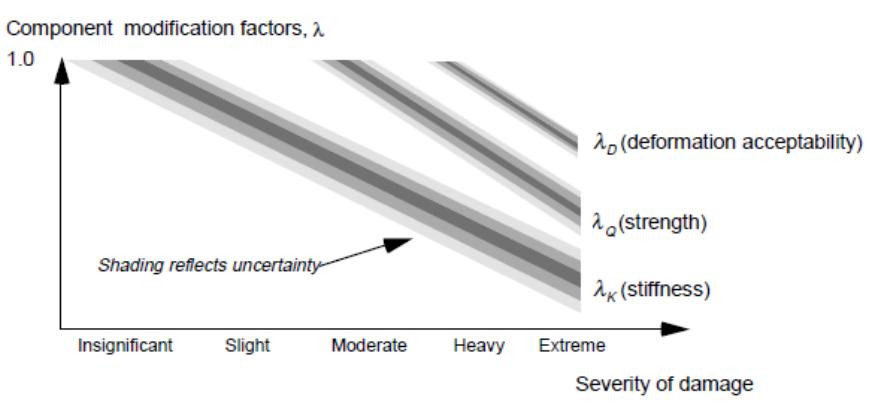

b)

Figure 3: a) Example of component damage classification for an isolated wall with ductile flexural behavior; b) general relationship between damage severity and modification factors [4].

Following the FEMA 306/307 approach, significant research effort has been dedicated in order to derive coefficient reduction factors for damaged structural elements as well as to define a detailed general framework for the evaluation of the residual capacity of RC buildings (e.g., [10, 11]). Nevertheless, these investigations mainly focused on frame systems (e.g., [1214]). Looking at structural walls, several experimental and numerical studies can be found in literature, however these research works focused at improving the understanding on the seismic response and performance of RC walls. Dashti et al. [15] developed a finite element model based on curved shell element formulation to predict the nonlinear behavior of planar RC structural walls with specific focus on out-of-plane instability mechanisms. Moreover, the same authors carried out a detailed experimental investigation on the out-of-plane instability in rectangular RC walls [16]. Shegay et al. [17] performed experimental testing on four flexural walls with rectangular cross sections in order to investigate the impact of the imposed axial load ratio as well as the transverse reinforcement detailing on their seismic performance. Niroomandi et al. [18] experimentally investigated the effects of the bi-directional loading on the seismic behavior of slender rectangular RC walls. An overview of comprehensive research programs, developed in New Zealand, following the 2010/2011 Canterbury earthquakes, and including practical recommendations for the design and assessment of RC walls, is available in Shegay et al. [19]. Li and Xiang [20] suggested a formulation for assessing the effective stiffness of RC squat structural walls by performing a comprehensive parametric study. A similar study was discussed in Sharifi and Shafieian [21], who proposed a formulation to de- 
termine the effective stiffness of slender and squat walls, based on statistical analyses of 154 existing experiments available in literature. Kolozvari et al. [22] developed an analytical model able to capture the interaction between axial/flexural and shear responses for RC walls subjected to reversed-cyclic, based on a two-dimensional fiber-based macroscopic model, and the experimental calibration and validation of this analytical wall model was also carried out [23]. Finally, a special collection of 10 papers presenting recent advances in seismic design of Reinforced Concrete walls can be found in Sritharan and Beyer [24]. However, as mentioned above, further investigations and research efforts are required to study and better understand the post-earthquake residual capacity of structural wall systems.

\section{PARAMETRIC INVESTIGATIONS ON RC WALLS}

A parametric analysis is carried out to investigate the seismic residual capacity of RC walls. After the collection of experimental literature data on structural walls, refined FEM models are implemented and calibrated by comparing numerical and experimental results. Then, additional case-study walls are defined by modifying the geometrical and structural details of the selected RC walls. Non-linear static analyses are thus performed to assess the seismic performance of the walls in their undamaged and damaged configurations. Different damage conditions as well as assessment methods are indeed considered. Finally, for each case-study wall system, strength and stiffness reduction factors are derived. Detailed information about the implemented methodology and the analysis results are reported within this section.

\subsection{RC wall configurations and modelling approach}

The case-study structural walls are selected from experimental tests available in literature and taking into account alternative collapse modes (i.e., flexural, flexural/shear and shear). Specifically, six experimental tests on structural walls are selected. Geometrical details and material properties of these RC walls are reported in Table 1. More details about the specimens can be found in the cited papers.

\begin{tabular}{lllllllllll}
\hline \multirow{2}{*}{ Author(s) } & ID & A.R. & $\mathrm{H}_{\mathrm{w}} / \mathrm{t}_{\mathrm{w}}$ & S.S.R. & $v$ & $\mathrm{f}_{\mathrm{c}}$ & $\mathrm{f}_{\mathrm{y}}$ & $\rho_{\mathrm{l}, \mathrm{BE}}$ & $\rho_{\mathrm{h}, \mathrm{web}}$ & Collapse \\
& Specimen & {$[-]$} & {$[-]$} & {$[-]$} & {$[-]$} & {$[\mathrm{MPa}]$} & {$[\mathrm{MPa}]$} & {$[\%]$} & {$[\%]$} & mode \\
\hline Thomsen and Wollace [25] & $\mathrm{RW} 2$ & 3.00 & 35.88 & 3.25 & 0.10 & 34.00 & 425.0 & 2.90 & 0.33 & Flexural \\
Dazio et al. [26] & WSH6 & 2.25 & 30.00 & 2.25 & 0.11 & 45.60 & 584.0 & 1.54 & 0.25 & Flexural \\
Tran and Wollace [27] & SP4 & 1.69 & 13.50 & 1.69 & 0.10 & 55.80 & 414.0 & 6.06 & 0.73 & Flexural/shear \\
Vallenas et al. [28] & S6 & 1.26 & 26.73 & 1.59 & 0.05 & 35.00 & 482.0 & 5.60 & 0.55 & Flexural/shear \\
Lefas et al. [29] & SW11 & 1.00 & 10.71 & 1.00 & 0.00 & 52.30 & 470.0 & 3.00 & 1.10 & Shear \\
Lefas et al. [29] & SW12 & 1.00 & 10.71 & 1.00 & 0.08 & 52.30 & 470.0 & 3.00 & 1.10 & Shear \\
\hline
\end{tabular}

Note: A.R. = Aspect Ratio; Hw = wall height; $t w=$ wall thickness; S.S.R. = Shear Span Ratio, $v=$ axial load ratio; f'c = concrete compression strength; fy $=$ steel yield stress; $\rho \mathrm{l}, \mathrm{BE}=$ boundary element longitudinal reinforcement ratio, $\rho \mathrm{h}, \mathrm{web}=\mathrm{web}$ horizontal reinforcement ratio.

Table 1: Geometrical details and material properties of the selected structural walls.

The structural walls are analyzed adopting a refined Finite Element Modelling approach based on the Modified Compression Field Theory (MCFT, Vecchio and Collins [30]). The MCFT is an analytical model for predicting the load-deformation response of reinforced concrete membrane elements subjected to shear and normal stresses. It is based on three sets of relationships: 1) compatibility relationships for concrete and reinforcement average strains; 2) equilibrium relationships involving average stresses in concrete and reinforcement; 3) constitutive relationships for cracked concrete and reinforcement [31]. 
The numerical analyses are performed using the structural software VecTor2 [6]. The reinforced concrete wall is modelled by plane stress rectangular elements. Steel transversal bars are modelled as smeared reinforcement in concrete elements, while steel longitudinal bars are represented by mono-dimensional "truss" elements. The Popovics [32] stress-strain relationship is adopted to model the (unconfined) concrete cover, while the Mander et al. [33] behavior is used for the (confined) concrete core. The steel stress-strain relationship is modeled according to Seckin [34], allowing to include the so-called Bauschinger effect. Figure 4 shows an example of structural wall numerical model in VecTor2 and the results obtained in terms of crack patterns (numerical vs. experimental).

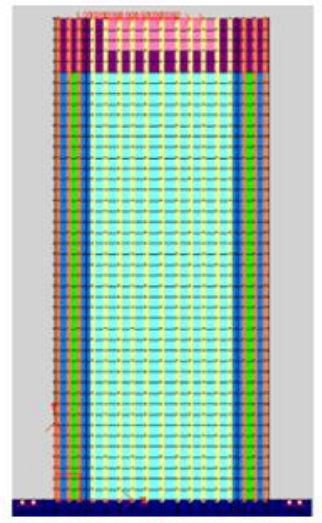

a)

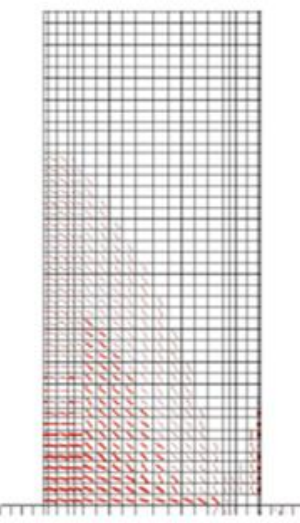

b)

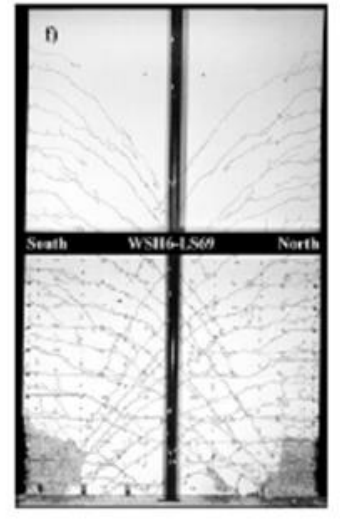

c)

Figure 4: Example of: a) numerical model in VecTor2; b) crack patterns obtained by VecTor2 vs c) crack patterns observed during the experimental tests performed by Dazio et al. [26].

For all the selected walls, numerical vs. experimental comparisons in terms of cyclic response and crack patterns are carried out. Results highlight a good agreement between numerical and experimental behavior, confirming the reliability of the adopted modelling approach. In Figure 5 an example of comparison in terms of cyclic response is presented for two flexural-dominated walls (for the walls affected by shear collapse mechanisms, only monotonic experimental curves are available).

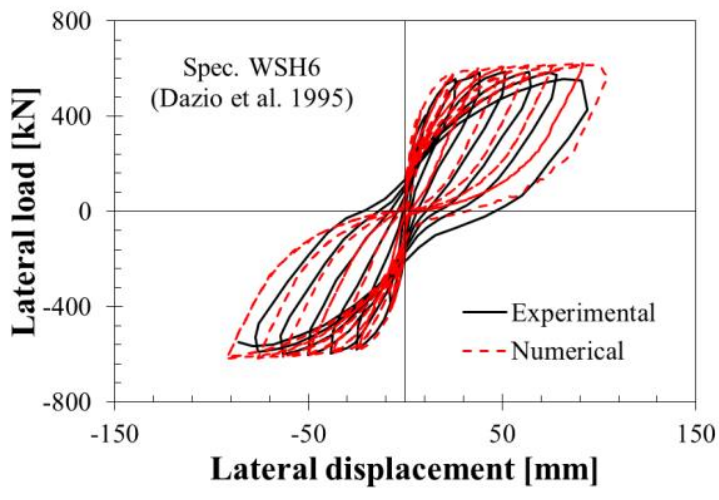

a)

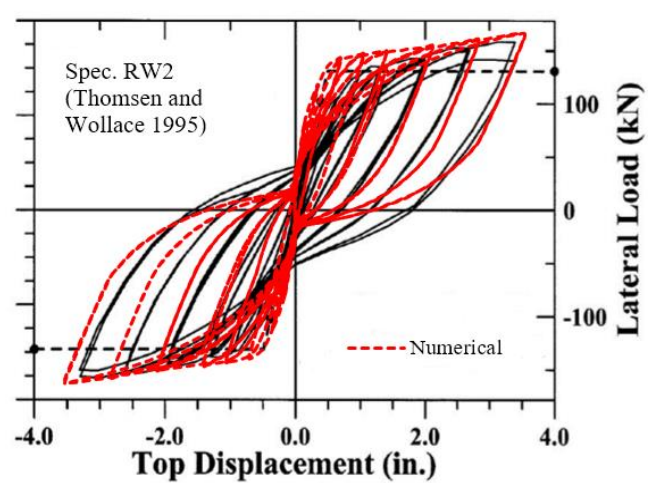

b)

Figure 5: Example of comparison in terms of cyclic response: a) Experimental data from Dazio et al. [26]; b) original graph from the experimental tests by Thomsen and Wallace [25].

In order to increase the dataset, parametric configurations of the RC walls listed in the previous Table 1 are identified and numerical analyses are simulated for each additional case- 
study adopting the same modelling approach previously described. Specifically, the walls are parameterized in terms of geometrical details (i.e., aspect ratio), applied axial load ( $v$ ) and material properties. It is worth noting that the expected behavior/collapse mode of the wall (flexural or shear or flexural/shear) can thus change, especially when the aspect ratio is modified. Table 2 summarizes the main properties of each structural wall considered to develop the parametric analysis. In total $39 \mathrm{RC}$ walls are involved (13 for each collapse mode).

\begin{tabular}{|c|c|c|c|c|c|c|c|c|c|}
\hline $\begin{array}{l}\text { Collapse } \\
\text { mode }\end{array}$ & $\begin{array}{l}\text { ID } \\
\text { Case-study }\end{array}$ & $\begin{array}{l}\text { A.R. } \\
{[-]}\end{array}$ & $\begin{array}{l}\mathrm{H}_{\mathrm{w}} / \mathrm{t}_{\mathrm{w}} \\
{[-]}\end{array}$ & $\begin{array}{l}\text { S.S.R. } \\
{[-]}\end{array}$ & $\begin{array}{l}v \\
{[-]}\end{array}$ & $\begin{array}{l}\mathrm{f}_{\mathrm{c}}^{\prime} \\
{[\mathrm{MPa}]}\end{array}$ & $\begin{array}{l}\mathrm{f}_{\mathrm{y}} \\
{[\mathrm{MPa}]}\end{array}$ & $\begin{array}{l}\rho_{\mathrm{l}, \mathrm{BE}} \\
{[\%]}\end{array}$ & $\begin{array}{l}\rho_{\mathrm{h}, \mathrm{web}} \\
{[\%]}\end{array}$ \\
\hline \multirow{13}{*}{ Flexural } & 1 & 3.00 & 35.88 & 3.25 & 0.10 & 34.00 & 425.0 & 2.90 & 0.33 \\
\hline & 2 & 3.00 & 35.88 & 3.25 & 0.10 & 45.60 & 425.0 & 2.90 & 0.33 \\
\hline & 3 & 3.00 & 35.88 & 3.25 & 0.10 & 34.00 & 584.0 & 2.90 & 0.33 \\
\hline & 4 & 3.00 & 35.88 & 3.25 & 0.10 & 34.00 & 425.0 & 6.00 & 0.33 \\
\hline & 5 & 2.25 & 30.00 & 2.25 & 0.11 & 45.60 & 584.0 & 1.54 & 0.25 \\
\hline & 6 & 2.25 & 30.00 & 2.25 & 0.055 & 45.60 & 584.0 & 1.54 & 0.25 \\
\hline & 7 & 2.25 & 30.00 & 2.25 & 0.22 & 45.60 & 584.0 & 1.54 & 0.25 \\
\hline & 8 & 2.25 & 30.00 & 2.25 & 0.11 & 34.00 & 584.0 & 1.54 & 0.25 \\
\hline & 9 & 2.25 & 30.00 & 2.25 & 0.11 & 45.60 & 584.0 & 2.90 & 0.25 \\
\hline & 10 & 3.00 & 32.13 & 3.00 & 0.08 & 52.30 & 470.0 & 3.00 & 1.10 \\
\hline & 11 & 3.00 & 32.13 & 3.00 & 0.08 & 34.00 & 470.0 & 3.00 & 1.10 \\
\hline & 12 & 3.00 & 32.13 & 3.00 & 0.08 & 52.30 & 584.0 & 3.00 & 1.10 \\
\hline & 13 & 3.00 & 32.13 & 3.00 & 0.08 & 52.30 & 470.0 & 6.00 & 1.10 \\
\hline \multirow{13}{*}{ Flexural/Shear } & 14 & 1.69 & 13.50 & 1.69 & 0.10 & 55.80 & 414.0 & 6.06 & 0.73 \\
\hline & 15 & 1.69 & 13.50 & 1.69 & 0.05 & 55.80 & 414.0 & 6.06 & 0.73 \\
\hline & 16 & 1.69 & 13.50 & 1.69 & 0.20 & 55.80 & 414.0 & 6.06 & 0.73 \\
\hline & 17 & 1.69 & 13.50 & 1.69 & 0.10 & 34.00 & 414.0 & 6.06 & 0.73 \\
\hline & 18 & 1.69 & 13.50 & 1.69 & 0.10 & 55.80 & 500.0 & 6.06 & 0.73 \\
\hline & 19 & 1.26 & 26.73 & 1.59 & 0.05 & 35.00 & 482.0 & 5.60 & 0.55 \\
\hline & 20 & 1.26 & 26.73 & 1.59 & 0.05 & 55.80 & 482.0 & 5.60 & 0.55 \\
\hline & 21 & 1.26 & 26.73 & 1.59 & 0.05 & 35.00 & 584.0 & 5.60 & 0.55 \\
\hline & 22 & 1.26 & 26.73 & 1.59 & 0.05 & 35.00 & 482.0 & 6.06 & 0.55 \\
\hline & 23 & 1.90 & 22.54 & 1.80 & 0.10 & 34.00 & 425.0 & 2.90 & 0.33 \\
\hline & 24 & 1.90 & 22.54 & 1.80 & 0.10 & 55.80 & 425.0 & 2.90 & 0.33 \\
\hline & 25 & 1.90 & 22.54 & 1.80 & 0.10 & 34.00 & 584.0 & 2.90 & 0.33 \\
\hline & 26 & 1.90 & 22.54 & 1.80 & 0.10 & 34.00 & 425.0 & 2.90 & 0.33 \\
\hline \multirow{13}{*}{ Shear } & 27 & 1.00 & 10.71 & 1.00 & 0.00 & 52.30 & 470.0 & 3.00 & 1.10 \\
\hline & 28 & 1.00 & 10.71 & 1.00 & 0.00 & 34.00 & 470.0 & 3.00 & 1.10 \\
\hline & 29 & 1.00 & 10.71 & 1.00 & 0.00 & 52.30 & 584.0 & 3.00 & 1.10 \\
\hline & 30 & 1.00 & 10.71 & 1.00 & 0.00 & 52.30 & 470.0 & 6.00 & 1.10 \\
\hline & 31 & 1.00 & 10.71 & 1.00 & 0.08 & 52.30 & 470.0 & 3.00 & 1.10 \\
\hline & 32 & 1.00 & 10.71 & 1.00 & 0.16 & 52.30 & 470.0 & 3.00 & 1.10 \\
\hline & 33 & 1.00 & 10.71 & 1.00 & 0.08 & 45.60 & 470.0 & 3.00 & 1.10 \\
\hline & 34 & 1.00 & 10.71 & 1.00 & 0.08 & 52.30 & 584.00 & 3.00 & 1.10 \\
\hline & 35 & 1.00 & 10.71 & 1.00 & 0.08 & 52.30 & 470.0 & 3.00 & 1.10 \\
\hline & 36 & 1.25 & 15.00 & 1.25 & 0.11 & 45.60 & 584.0 & 1.54 & 0.25 \\
\hline & 37 & 1.25 & 15.00 & 1.25 & 0.11 & 52.30 & 584.0 & 1.54 & 0.25 \\
\hline & 38 & 1.25 & 15.00 & 1.25 & 0.11 & 45.60 & 470.0 & 1.54 & 0.25 \\
\hline & 39 & 1.25 & 15.00 & 1.25 & 0.11 & 45.60 & 584.0 & 3.00 & 0.25 \\
\hline
\end{tabular}

Note: A.R. $=$ Aspect Ratio; $\mathrm{H}_{\mathrm{w}}=$ wall height; $\mathrm{t}_{\mathrm{w}}=$ wall thickness; $\mathrm{S} . \mathrm{S} . \mathrm{R}=$ Shear Span Ratio, $v=$ axial load ratio; $\mathrm{f}^{\prime}{ }_{\mathrm{c}}=$ concrete compression strength; $f_{y}=$ steel yield stress; $\rho_{\mathrm{l}, \mathrm{BE}}=$ boundary element longitudinal reinforcement ratio, $\rho_{\mathrm{h}, \mathrm{web}}=$ web reinforcement ratio 


\subsection{Non-linear static analyses}

Non-linear static analyses are performed to assess the seismic performance of all the casestudy structural walls in their pre- (undamaged) and post- earthquake (damaged) conditions. In particular, three post-earthquake damage levels are considered, namely: DS1 (limited damage), DS2 (moderate damage) and DS3 (severe damage). Nevertheless, in the international codes/guidelines practical and specific methods to identify these damage states are still under development, while only a qualitative damage description is often reported. Therefore, in this paper three alternative methods are considered and compared to identify the three damage levels for each wall configuration:

- The first method (M1) refers to the FEMA 307 [9] approach. Damage severity levels are correlated with the achievement of displacement ductility levels. More details about the FEMA 307 evaluation procedure are reported in the previous section.

- The second method (M2) refers to the fragility database of FEMA P-58 [35]. The existing repository of fragility data allows to identify the damage states by the achievement of specific drift levels and damage conditions (e.g. dimensions of cracking in concrete).

- The third method (M3) refers to the damage classification of FEMA 306 [4]. Specifically, as mentioned above, FEMA 306 provides crack pattern information associated with different damage severity levels and this description can be used to identify different damage levels.

A unidirectional monotonic lateral load is initially applied to each wall in order to evaluate the force-displacement capacity curve in its undamaged configuration. Then, a two-step procedure is adopted: 1) first, reversed-cyclic loads are applied to simulate the achievement of specific damage states (i.e., DS1, DS2, DS3) considering the identification methods described above (i.e., M1 vs. M2 vs. M3); 2) then, a unidirectional monotonic lateral load is applied to the damaged walls to evaluate the force-displacement capacity curve for each damaged configuration. This allows to derive stiffness and strength reduction coefficients (i.e., $\lambda_{\mathrm{K}}$ and $\lambda_{\mathrm{Q}}$ ) by comparing the pre- and post- earthquake force-displacement curves. It is worth noting that a bilinearization of the capacity curves is needed to compute these reduction factors. In this work, two different bilinearization methods are considered, according to the procedure proposed by Paulay and Priestley [36] and FEMA 273 [37] (referred to as B1 and B2 respectively), and compared. The first approach provides the secant stiffness intersecting the pushover curve at $0.75 \mathrm{~V}_{\mathrm{u}}$, where $\mathrm{V}_{\mathrm{u}}$ is the average of the maximum shear values at the base of the wall, while for the second method the intersection point is identified at $0.6 \mathrm{~V}_{\mathrm{y}}$, where $\mathrm{V}_{\mathrm{y}}$ is now the wall yielding shear.

Figure 6 shows an example of load history adopted in the two-step non-linear static analysis of damaged wall configurations as well as an example of assessment of reduction factors through the capacity curves of both the undamaged and damaged wall (B2 bilinearization, DS3 level). In summary, three different damaged states are considered for each case-study wall by adopting three different damage identification methods (M1, M2, M3). Moreover, reduction factors are derived according to two alternative bilinearization methods (B1, B2). This leads to a total number of 702 values for both strength and stiffness reduction factors. 


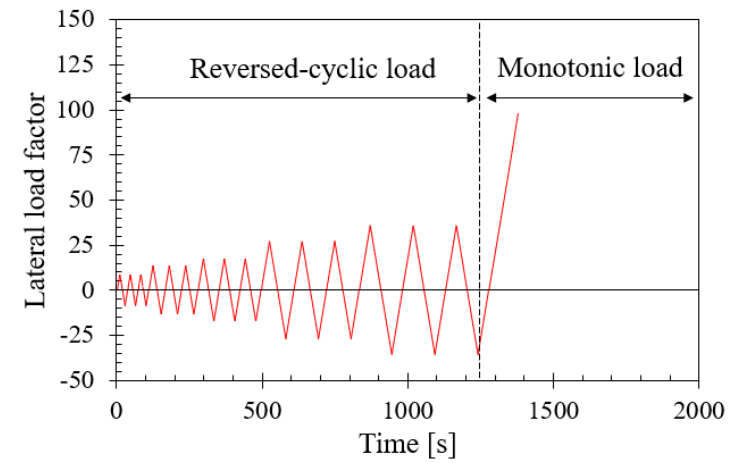

a)

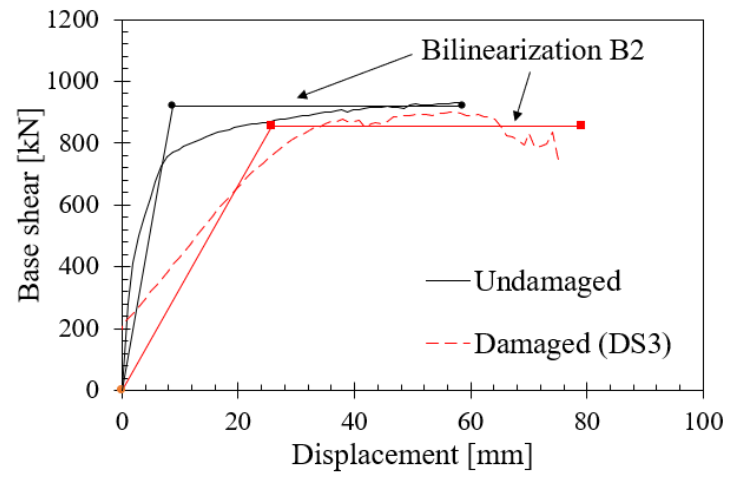

b)

Figure 6: a) Load history for the non-linear static analysis of damaged walls; b) assessment of reduction factors by comparing the capacity curves of the undamaged and damaged wall (e.g., B2 bilinearization, DS3 level).

\subsection{Reduction coefficients}

Results in terms of strength and stiffness reduction factors (as percentage values [\%]) are summarized in Table 3. The structural walls are classified according to their collapse mechanism mode and for each damaged state (DS1, DS2, DS3) and identification method (M1, M2, M3), as well as bilinearization procedure (B1, B2), average and dispersion (standard deviation) values of reduction factors are reported.

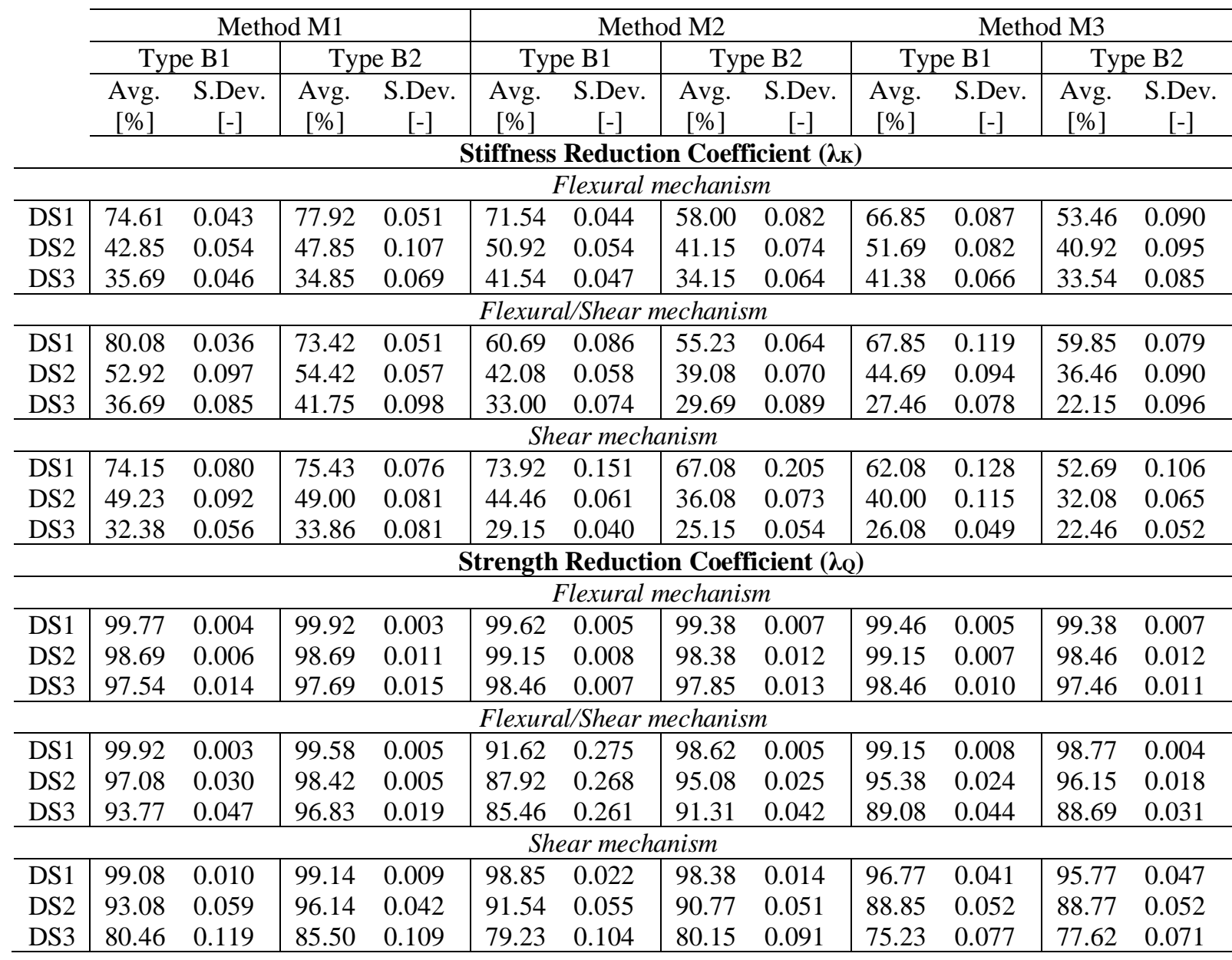

Table 3: Reduction coefficients obtained for the case-study walls. 
Results highlight that stiffness is more sensitive to damage when compared to strength, and this is in agreement with FEMA 306. Moreover, the obtained mean reduction values are lower (especially in case of $\lambda_{\mathrm{K}}$ ) when compared to DS1/DS2/DS3 reduction coefficients of 80/60/50 and 100/100/80 for $\lambda_{\mathrm{K}}$ and $\lambda_{\mathrm{Q}}$, respectively, provided by FEMA 306 for flexural walls. Referring to the severe damage state (DS3), the strength loss obtained for flexural-dominated walls is less than 5\%, while is around 10-15\% for flexural/shear walls and almost $20-25 \%$ for walls affected by shear collapse. On the other hand, referring to the same damage level, higher stiffness losses can be observed for all the wall typologies, even more than $70 \%$ at DS3. The previous table also shows that walls with shear collapse mechanism have higher dispersion in the results, as highlighted in Figure 7a for the case of Method M1-Bilinearization B2. Furthermore, differences (less than $10 \%$ for M1, while less than $20 \%$ for M2, M3) can be highlighted when the two bilinearization methods (B1 vs. B2) are compared (Figure 7). Finally, it is worth noting that the damage assessment methods strongly affect the results. In fact, adopting the M1 method the lowest dispersion is found, while the M3 method leads to the highest dispersion values. This result is in agreement with the expectation, since referring to crack patterns (M3 method) can lead to higher uncertainty in the identification of damage states than using a direct indicator as the displacement ductility (M1 method).

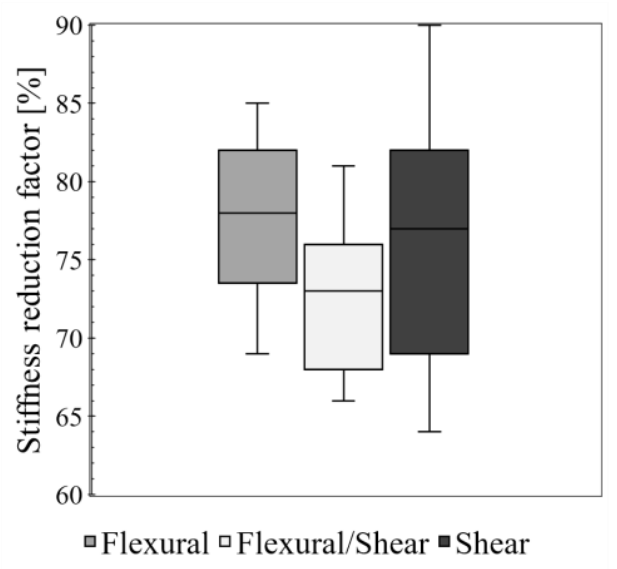

a)

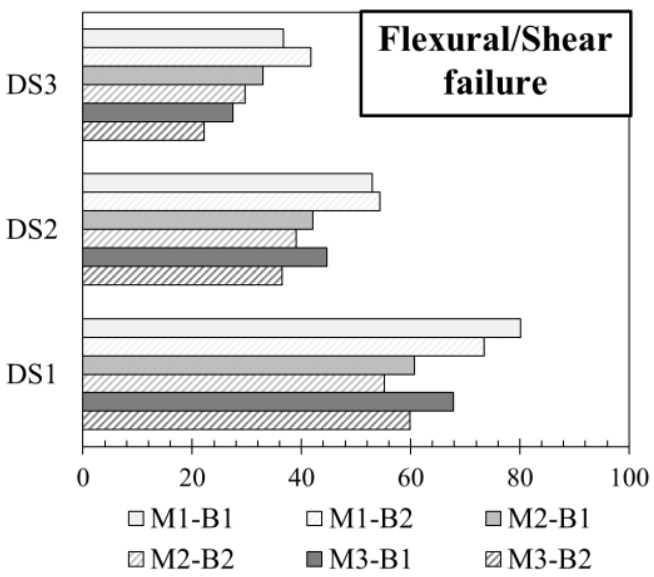

c)

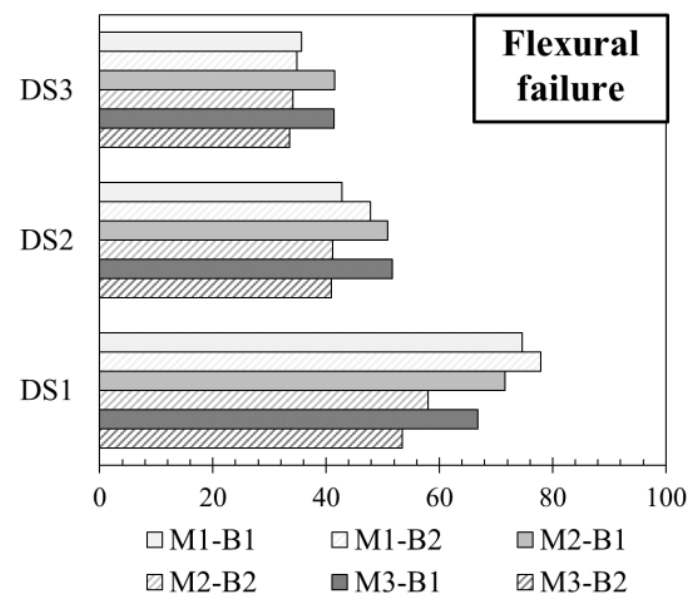

b)

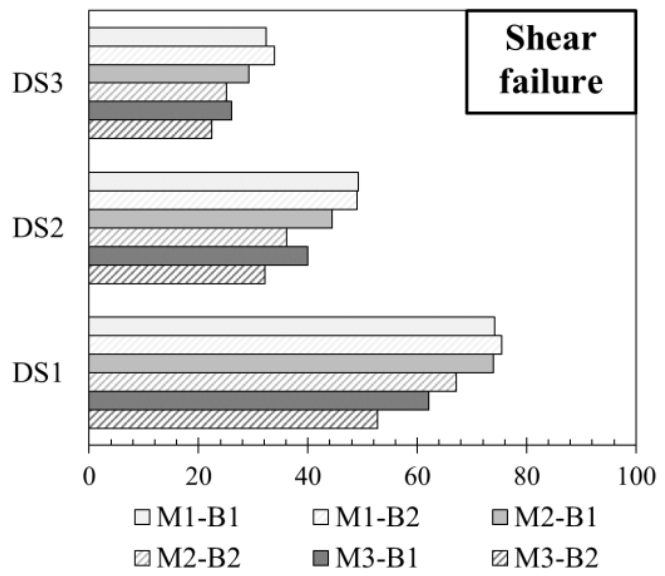

d)

Figure 7: a) Mean and dispersion values of stiffness reduction factors $\lambda_{\mathrm{K}}$ (for Method M1 and Bilinearization B2); comparison between the $\lambda_{\mathrm{K}}$ values obtained from all the implemented approaches, in case of: b) flexural failure; c) flexural/shear failure; d) shear failure. 


\section{NUMERICAL ANALYSIS ON A MULTI-STORY RC BUILDING}

\subsection{Description of the case-study}

The case-study building is a 5-story reinforced concrete structure with global dimensions and plan geometry as presented in Figure 8. This structure is selected from a previous research work developed by Bianchi et al. [38]. The structural skeleton consists of seismic resistant four-bay frames in one direction and seismic-resistant walls in the orthogonal direction. The building has commercial and residential use and is located in a high-seismicity Italian zone (PGA of $0.353 \mathrm{~g}$ ). Focusing on the wall direction, alternative typologies of structural systems are designed to provide the same Overturning Moment (OTM of $35000 \mathrm{kNm}$ ) of the initial reference multi-story building, namely: 1) a first case-study comprising four earthquake-resistant ductile walls, characterized by a flexural collapse mechanism (Case 1);2) a second case-study consisting of the same geometrical configuration, but the RC walls are now affected by a brittle shear failure, i.e. no hierarchy of strengths principles is applied (Case 2). Although the reference building is a new structure, the shear-dominant walls are designed for the purpose of this study only.

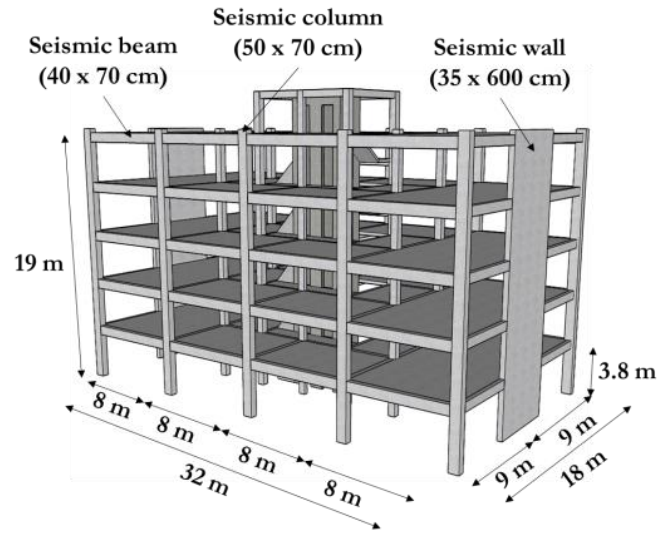

a)

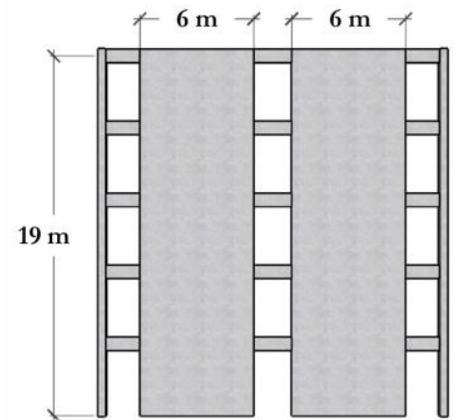

CASE 1: Flexural failure mode CASE 2: Shear failure mode

b)

Figure 8: a) Global view of the reference building (Bianchi et al. [38]; b) new geometrical configuration designed in the wall direction (Case 1: flexural collapse; Case 2: shear collapse)

\subsection{Numerical analysis}

Non-linear static (pushover) analyses are performed following an analytical-based approach, the so-called Simple Lateral Mechanism Analysis (SLaMA) described in the NZSEE guidelines [39-41]. This practical methodology allows to determine the base sheardisplacement (capacity) curves of the two case-study wall systems by simple analytical calculations accounting for the collapse mechanism (flexure, shear, flexure/shear) developing within the structural system. Then, following the pushover-based Capacity Spectrum Method [42, 43], the building performance points are computed at different seismic intensity levels (namely SLO, SLD, SLV, SLC, or, Immediate Operational, Damage Control, Life Safety and Collapse Prevention, respectively, as indicated in the NTC 2018 [44]).

Figure $9(\mathrm{a}, \mathrm{c})$ shows the demand vs. capacity results obtained in the AccelerationDisplacement Response Spectrum (ADRS) domain. This figure highlights the better behavior of the ductile flexural walls, even allowing for a greater dissipation and consequently a reduced seismic demand (response spectra at Ultimate Limit States are in fact reduced considering the building equivalent viscous damping). Instead, the shear-dominated walls are 
characterized by a brittle behavior leading to a ultimate capacity point not even achieving the Life-Safety design spectrum. Finally, the damaged configurations for the two case-studies (Case 1, Case 2) are determined applying the reduction strength/stiffness coefficients already computed in the previous section (Figure $9 \mathrm{~b}, \mathrm{~d}$ ).

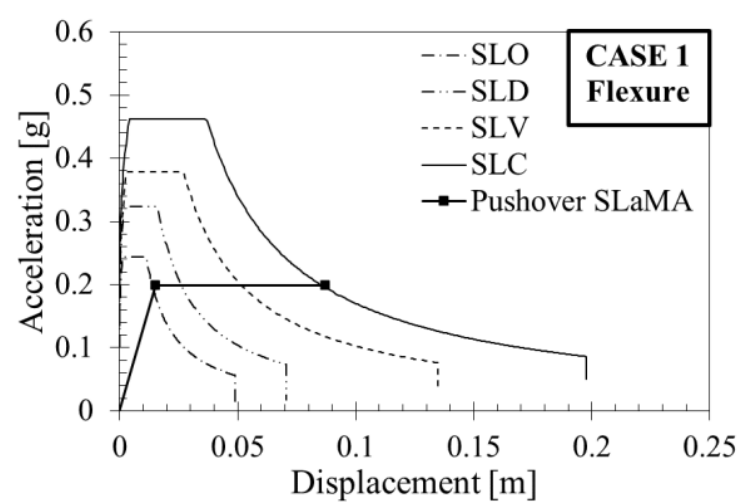

a)

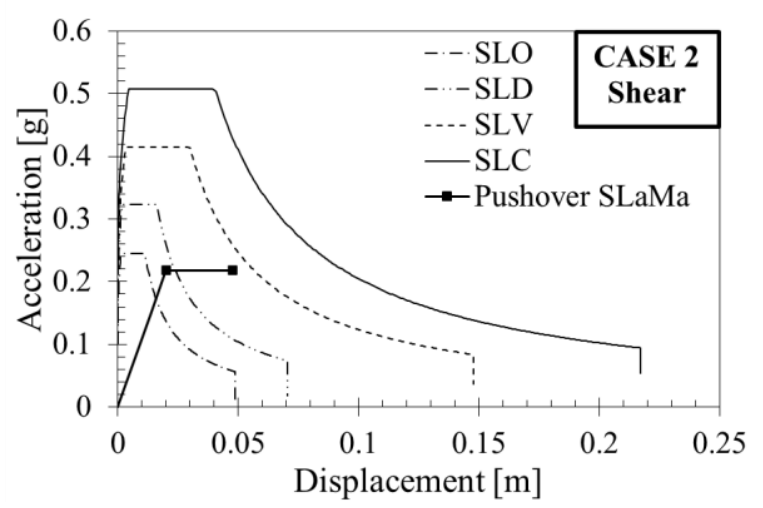

c)

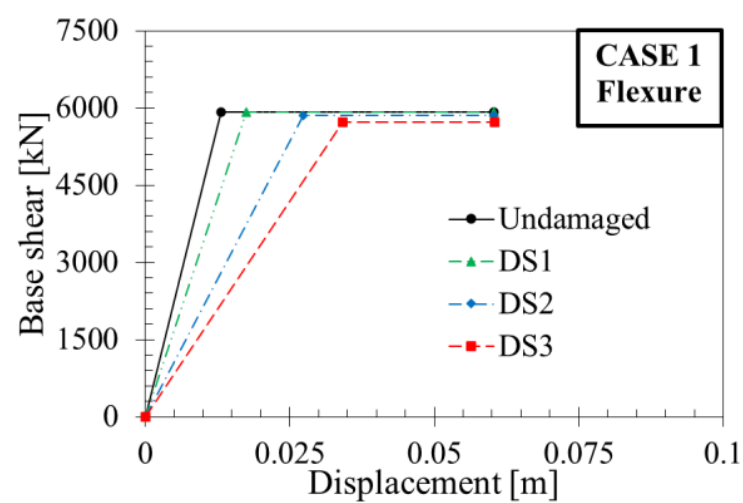

b)

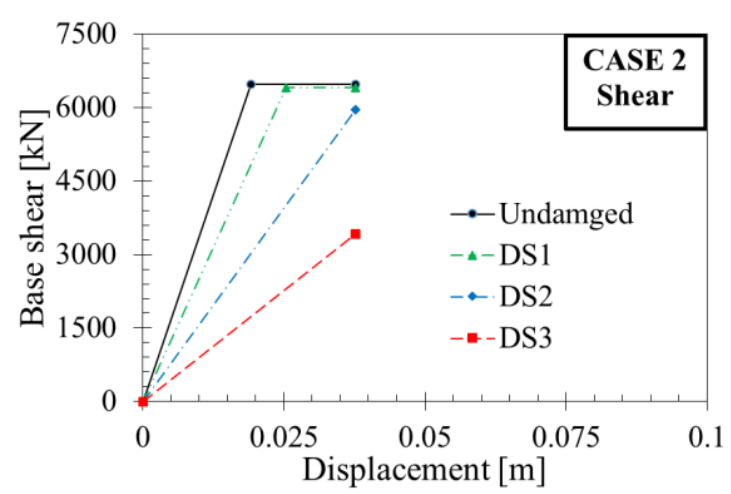

d)

Figure 9: Capacity curves of the undamaged structure in the Acceleration-Displacement Response Spectrum (ADRS) domain and for all the damaged wall configurations (DS1, DS2, DS3): a) b) Case 1 - flexural failure mode; c) d) Case 2 - shear failure mode.

\subsection{Loss assessment investigations}

Loss assessment analyses are finally implemented considering as input data the floor accelerations and inter-story drift ratios (from the performance points) obtained at the various seismic intensities. Two alternative loss assessment procedures are involved: 1) the simplified approach described in the D.M. 65 [45], the "Seismic-Bonus" guidelines; 2) the rigorous probabilistic-based procedure defined in FEMA P-58 [35].

Focusing on the simplified methodology, results in terms of Expected Annual Losses (EAL) curves and values (expressed as percentage of the Replacement Cost - RC) are summarized in Figure 10 (referring to M1 damage assessment method and B1 bilinearization method) for both undamaged and damaged wall systems. The comparison highlights that the structural system comprising brittle RC walls (Case 2) leads to higher losses when compared to the structural configuration consisting of ductile walls (Case 1). Furthermore, for Case 1 and looking at DS1 damage level (and DS2 in some cases), lower economic losses are found when compared to the undamaged structure. This is due to the structural system yielding before the expulsion of the external infill walls (expected to be achieved at $0.5 \%$ drift level as per Italian NTC 2018 code [44]). Thus, the cost/frequency point at SLD is now represented by the yield- 
ing of the steel rebars, causing reduced repair costs instead of the pre-fixed value imposed by D.M. 65 [45] at SLD, i.e. 15\% RC (this value has been derived from the reconstruction/repair costs after L'Aquila earthquake - White Book, Dolce and Manfredi [46] - already including the contribution of non-structural damage, especially masonry infill walls).

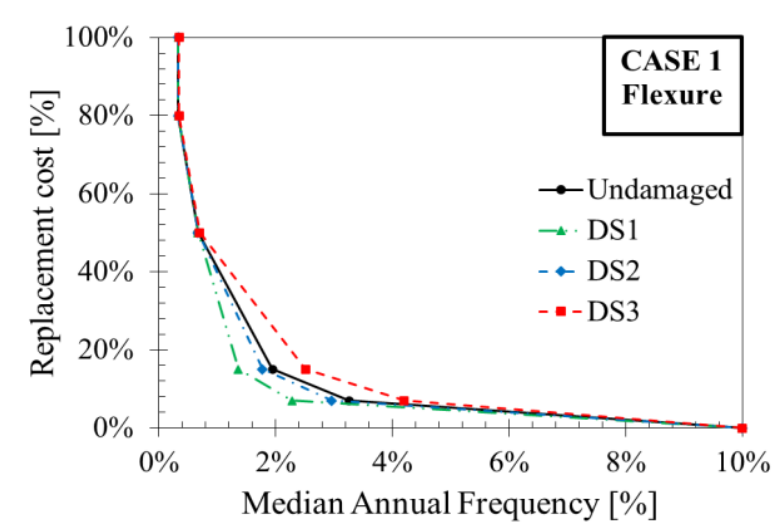

a)

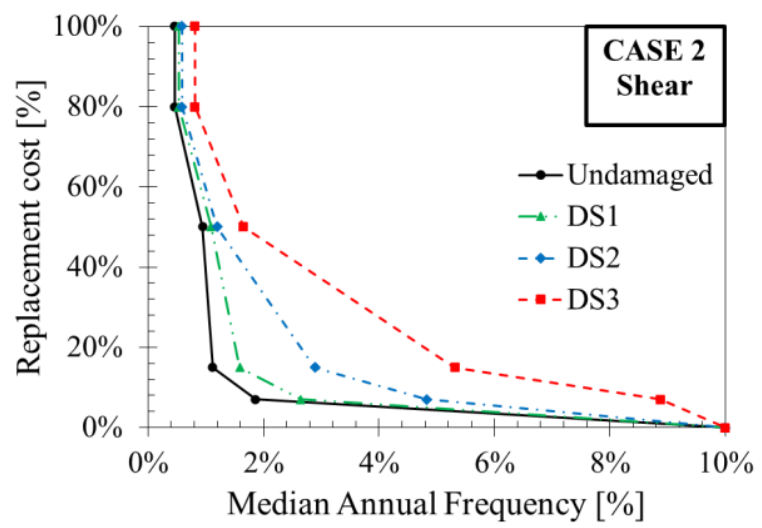

c)

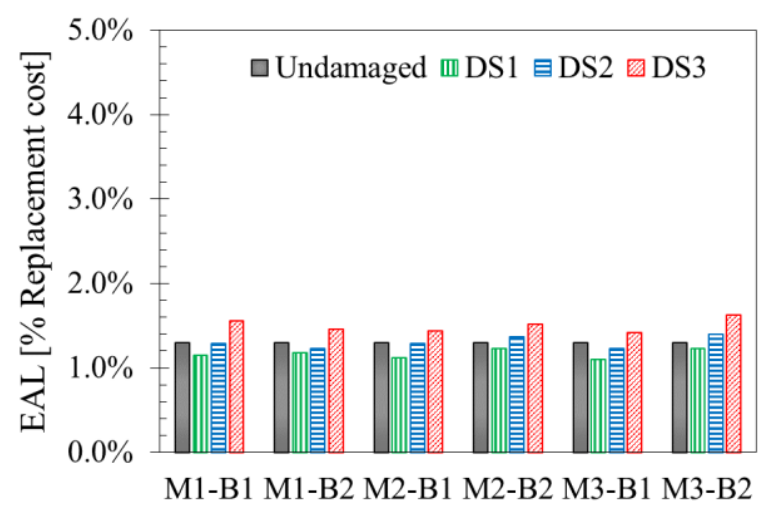

b)

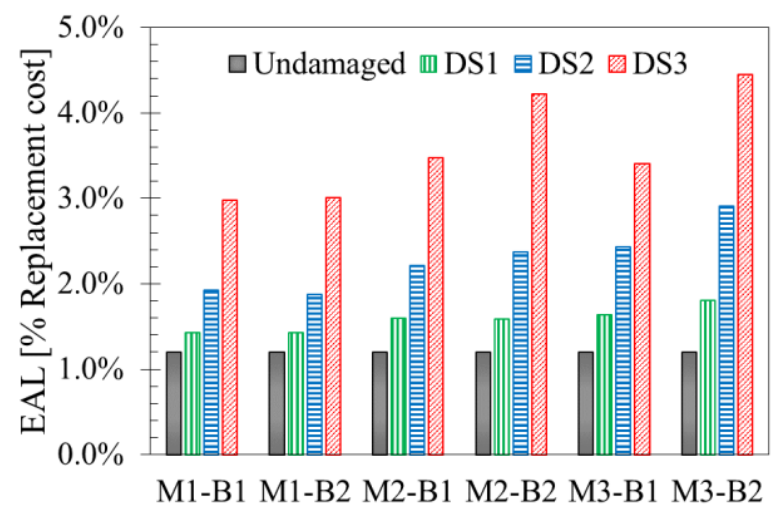

d)

Figure 10: EAL curves and values for the undamaged and damaged wall systems: a) b) Case 1 (flexural collapse mode); c) d) Case 2 (shear collapse mode).

Consequently, looking at the yielding point as damage limit for SLD and following the analytical-based codified loss assessment approach, the lower elastic stiffness of the structure in case of DS1 (or DS2) inherently brings to lower losses (Figure 11). Therefore, losses are not properly evaluated for the flexural-dominated wall configurations at SLD (and consequently at SLO). In general, this outcome highlights the limits of the current code-compliant procedure, not accounting for the possibility of adjusting the repair cost/frequency values when a specific damage condition is achieved. In this case, the very stiff structural walls begin to damage at drift levels lower than the $0.5 \%$ (or greater) value, representing the displacement check/verification at low seismic intensity levels within the Italian Code [44]. Nevertheless, referring to international codes (as SEAOC Vision 2000 [47], NZS 1170.5 [48]), useful indications can be found to evaluate proper drift limiting values at Damage Control level for the case of wall structural typology. 


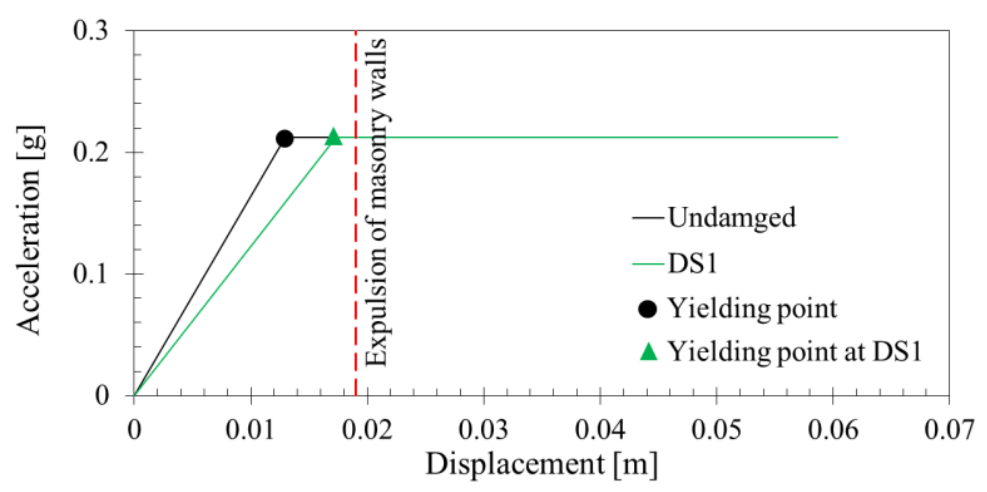

Figure 11: Comparison between undamaged and damaged (DS1) response for Case 1 (flexural collapse).

In order to obtain a more accurate evaluation of the EAL values, loss assessment analyses are also implemented using the PACT (Performance Assessment Calculation Tool) provided by the FEMA P-58[35]. This tool allows to include all the component fragilities of the building under consideration, thus the issue previously highlighted for the simplified procedure is automatically solved. In fact, the methodology is flexible and opened to the possibility of including new fragility functions, as well as consequence functions, describing the behavior of specific building structural and non-structural elements. In this case, due to the absence of fragility curves representing the Italian clay-brick masonry infill walls within the available fragility database, these functions are added by referring to the data reported in Cardone et al. [49]. Table 4 summarizes the EAL values obtained from both loss assessment methodology for both (undamaged) case-studies. It can be highlighted that the probabilistic procedure leads to reduced repair cost values and, consequently, an improved risk class for the building, as observed for the case of flexural collapse mechanism.

\begin{tabular}{cccccc}
\cline { 2 - 5 } & \multicolumn{2}{c}{ EAL [\%RC] } & \multicolumn{2}{c}{ Risk class } \\
\hline Case-study & Collapse mode & D.M. 65 & FEMA P-58 & D.M. 65 & FEMA P-58 \\
\hline Case 1 & Flexural & 1.30 & 0.84 & B & A \\
Case 2 & Shear & 1.20 & 1.04 & B & B \\
\hline
\end{tabular}

Table 4: EAL values for D.M. 65 and FEMA P-58 loss assessment methodology for undamaged case-studies

Ultimately, another decision variable useful to provide indications on the seismic performance of a building system (as well as addressing the design of new and/or retrofitted buildings, as described in the research work by Nuzzo et al. [50]) is represented by the expected Probable Maximum Loss (PML). This parameter provides the maximum probable building repair cost associated with a specific intensity level. Figure 12 presents the PML curves obtained from PACT tool for both case-study structures. This graph highlights how losses can be high even at low-intensity seismic levels and that higher values are obtained for the structural walls affected by shear collapse mechanism (40\% more than the flexural case when looking at the maximum expected loss of Figure 12a). 


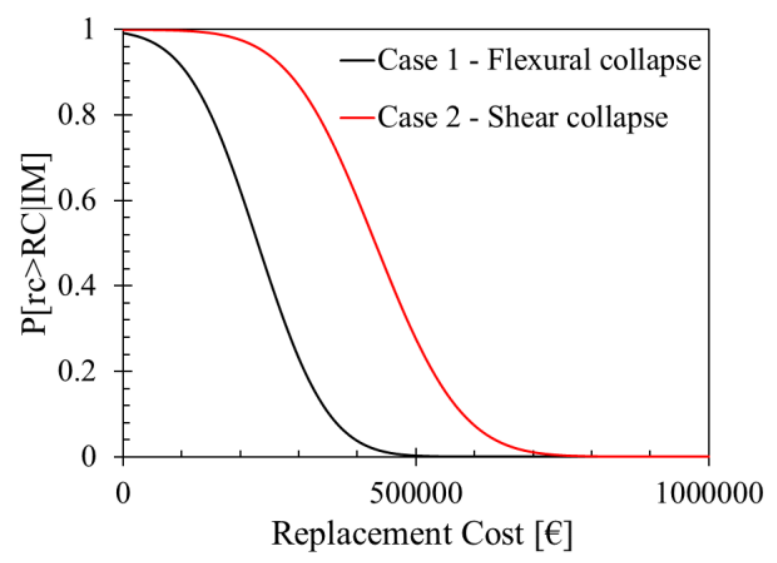

a)

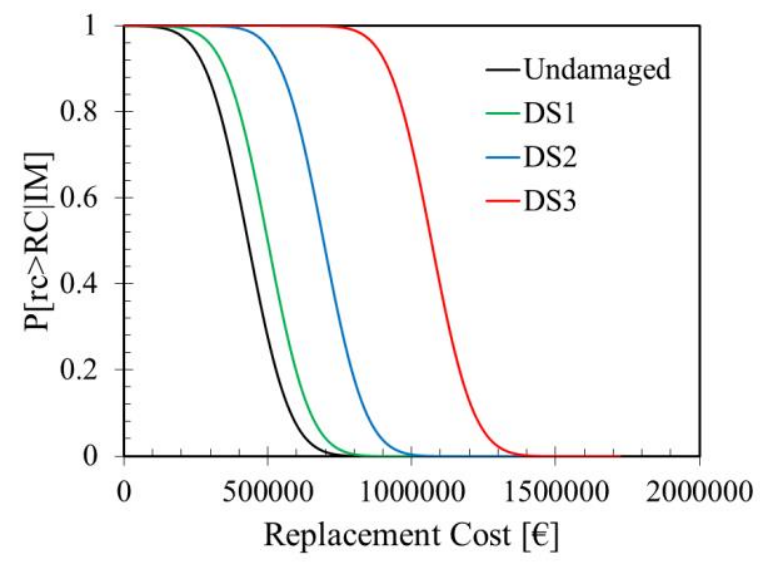

b)

Figure 12: PML curves obtained through the FEMA P-58 methodology: a) comparison between Case 1 (flexural collapse mode) and Case 2 (shear collapse mode); b) at various damage levels for Case 2 (shear collapse mode).

The FEMA-based loss assessment results in terms of EAL/PML values are presented for the undamaged structural configurations (Case 1 vs. Case 2), with the aim of defining more reliable loss values through a more accurate prediction of the repair costs. When considering the damaged cases (DS1, DS2, DS3), the probabilistic-based procedure as developed within the PACT tool does not allow (yet) to properly consider the cumulative damage associated with the wall systems, i.e. to evaluate PML/EAL results for the damage wall configurations. In fact, modifications of the probabilistic formulations (conditional probability) as well as cumulative-based fragility/consequence functions should be considered. Therefore, in order to highlight the possible effect of the damage state into the loss assessment results (from a conceptual point of view), Figure 12b presents the PML curves obtained for the damaged structural cases when the same relative difference in losses obtained from the simplified assessment is adopted.

\section{CONCLUSIONS}

This paper investigated the seismic residual capacity of RC structural walls through numerical (non-linear cyclic/static, FEM/macro-modelling) analyses and loss assessment studies. The research work aimed at providing indications on the methodology to be followed in order to include residual capacity considerations in practical applications. Therefore, alternative damage assessment methods were used (or proposed) and compared to define specific damage limit states (DS1: light, DS2: moderate, DS3: severe) and the related stiffness/strength reduction coefficients for RC walls affected by either a flexural and/or shear collapse mechanism. Moreover, loss investigations on a multi-story case-study building were developed to study the effect of the damage level and type of collapse mechanism into the repair costs of structural wall systems.

The main results from the developed study are herein discussed:

- FEMA 306/307 (1998) guidelines do not provide a standardized procedure to identify the different damage states levels (DS1, DS2, DS3) in RC structural walls (e.g. in case of experimental testing, indications on the specific load history to be adopted are missing). Comparing alternative damage assessment methods, less dispersion in the results in terms of stiffness/strength reduction coefficients is related to the adoption of the 
FEMA 307 procedure (describing the damage states by the achievement of specific ductility levels);

- Loss assessment results in terms of EAL highlight the importance of including residual capacity considerations in the analysis. This could provide valuable information to support decisions on the post-earthquake repair/retrofit/demolition. In fact, results highlight that greater losses are obtained even at low-intensity levels when the response of the damaged wall is considered, when compared to the undamaged wall. Moreover, when repair/rehabilitation actions need to be implemented for existing wall systems, higher attention should be paid in case of walls with brittle (shear-dominated) behavior, leading to substantial economic losses at increased damage levels.

- The simplified procedure reported in the "Sesmic-Bonus" is not able to consider realistic repair costs at low seismic intensity levels in case of stiff $\mathrm{RC}$ wall systems. This is due to the codified analytical procedure based on economic losses from L'Aquila 2009 earthquake accounting for alternative structural typologies and non-structural damage (especially unreinforced masonry walls). This issue could be solved by referring to post-earthquake reports and extrapolating the data related to the RC buildings only, as well as modifying the definition of the low-intensity (SLD) cost/frequency points following international codes/guidelines indications (drift limits in case of wall systems).

Nevertheless, this research work represents a preliminary parametric analysis and investigation on the residual capacity for RC walls. Further studies are needed to provide general indications on the reduction strength/stiffness coefficients to be used in practical applications, for specific wall typologies/structural response. Moreover, additional and more refined investigations (numerical modelling, time-history analysis) are needed to study the residual capacity of multi-story wall structures as well as to determine the consequent socio-economic losses even by the implementation of a more refined procedure taking into account the cumulative damage within the building elements.

\section{REFERENCES}

[1] M. Maeda, H. Al-Washali, K. Matsukawa, An overview of post earthquake damage and residual capacity evaluation for reinforced concrete buildings in Japan. 7th International Conference on Computational Methods in Structural Dynamics and Earthquake Engineering (COMPDYN 2019). Crete, Greece, June 24-26, 2019.

[2] W.Y. Kam, S. Pampanin, K. Elwood, Seismic performance of reinforced concrete buildings in the 22 February Christchurch (Lyttelton) earthquake. Bulletin of the New Zealand Society for Earthquake Engineering 44(4), 239-278, 2011.

[3] J.W. Wallace, L. M. Massone, P. Bonelli, J. Dragovich, R. Lagos, C. Lüders, J. Moehle, Damage and implications for seismic design of RC structural wall buildings. Earthquake Spectra, 28(1), 281-299, 2012.

[4] Federal Emergency Management Agency, Evaluation of Earthquake Damaged Concrete and Masonry Wall Buildings - Basic procedures manual. FEMA 306, Washington DC, 1998. 
[5] The Japan Building Disaster Prevention Association (JBDPA), Guideline for Postearthquake Damage Evaluation and Rehabilitation. (in Japanese), 1991, revised in 2001 and 2015.

[6] F.J. Vecchio, Nonlinear finite element analysis of reinforced concrete membranes. ACI Structural Journal, 86(1), 26-35, 1989.

[7] W.T. Holmes, Policies and standards for reoccupancy repair of earthquake-damaged buildings. Earthquake spectra, 10(1), 197-208, 1994.

[8] Y. Nakano, M. Maeda, H. Kuramoto, M. Murakami, Guideline for post-earthquake damage evaluation and rehabilitation of RC buildings in Japan. 13th World Conference on Earthquake Engineering. Vancouver, B.C., Canada, August 1-6, 2004.

[9] Federal Emergency Management Agency, Evaluation of Earthquake Damaged Concrete and Masonry Wall Buildings - Technical Resources. FEMA 307, Washington DC, 1998.

[10] M. Polese, M. Di Ludovico, A. Prota, G. Manfredi, Damage-dependent vulnerability curves for existing buildings. Earthquake engineering \& structural dynamics, 42(6), 853-870, 2013.

[11] K.J. Elwood, K. Marder, S. Pampanin, A. Cuevas Ramirez, M. Kral, P. Smith, A. Cattanach, M. Stannard, Draft framework for assessing residual capacity of earthquakedamaged concrete buildings. Proceedings of The New Zealand Society for Earthquake Engineering Annual Technical Conference, 2016.

[12] M. Di Ludovico, M. Polese, M. Gaetani d'Aragona, A. Prota, G. Manfredi, A proposal for plastic hinges modification factors for damaged RC columns. Engineering Structures, 51, 99-112, 2013.

[13] K. Marder, C. Motter, K.J. Elwood, G. Charles Clifton, Testing of 17 identical ductile reinforced concrete beams with various loading protocols and boundary conditions. Earthquake Spectra, 34(3), 1025-1049, 2018.

[14] K. Marder, K.J. Elwood, C.J. Motter, G. Charles Clifton. Post-earthquake assessment of moderately damaged reinforced concrete plastic hinges. Earthquake Spectra, 36(1), 299-321, 2020.

[15] F. Dashti, R.P. Dhakal, S. Pampanin, A parametric investigation on applicability of the curved shell finite element model to nonlinear response prediction of planar RC walls. Bulletin of Earthquake Engineering, 17(12), 6515-6546, 2019.

[16] F. Dashti, R.P. Dhakal, S. Pampanin., Evolution of out - of - plane deformation and subsequent instability in rectangular RC walls under in - plane cyclic loading: Experimental observation. Earthquake Engineering \& Structural Dynamics, 47(15), 29442964, 2018.

[17] A.V Shegay, C.J. Motter, K.J. Elwood, R.S. Henry. Impact of axial load on the seismic response of rectangular walls. Journal of Structural Engineering, 144(8), 04018124, 2018.

[18] A. Niroomandi, S. Pampanin, R.P. Dhakal, M.S. Ashtiani, R. Nokes. Experimental study on the effects of bi - directional loading pattern on rectangular reinforced concrete walls. Earthquake Engineering \& Structural Dynamics, 1-21, 2021. 
[19] A.V. Shegay, F. Dashti, L. Hogan, Y. Lu, A. Niroomandi, P. Seifi, T. Zhang, R.P. Dhakal, K.J. Elwood, R.S. Henry, S. Pampanin, Research programme on seismic performance of reinforced concrete walls. Bulletin of the New Zealand Society for Earthquake Engineering, 53(2), 54-69, 2020.

[20] B. Li, W. Xiang, Effective stiffness of squat structural walls. Journal of Structural Engineering, 137(12), 1470-1479, 2011.

[21] M. Sharifi, M. Shafieian, Effective stiffness of concrete shear walls based on statistical analysis. Structural Concrete, 19(6), 1560-1576, 2018.

[22] K. Kolozvari, K. Orakcal, J.W. Wallace, Modeling of cyclic shear-flexure interaction in reinforced concrete structural walls. I: Theory. Journal of Structural Engineering, 141(5), 04014135, 2015.

[23] K. Kolozvari, T.A. Tran, K. Orakcal, J.W. Wallace, Modeling of cyclic shear-flexure interaction in reinforced concrete structural walls. II: Experimental validation. Journal of Structural Engineering, 141(5), 04014136, 2015.

[24] S. Sritharan, K. Beyer, Special Collection on Recent Advances in Reinforced Concrete Walls Designed to Resist Seismic Loads. Journal of Structural Engineering, 144(9), 02018002, 2018.

[25] J.H. Thomsen, J.W. Wallace, Displacement-based design of reinforced concrete structural walls: Experimental studies of walls with rectangular and T-shaped cross sections. Rep. No. CU/ CEE-95/06, Department of Civil and Environmental Engineering, Clarkson University, Potsdam, N.Y, 1995.

[26] A. Dazio, K. Beyer, H. Bachmann, Quasi-static cyclic tests and plastic hinge analysis of RC structural walls. Engineering Structures, 31(7), 1556-1571, 2009.

[27] T.A. Tran, J.W. Wallace, Experimental study of nonlinear flexural and shear deformations of reinforced concrete structural walls. Proceedings, 15th World Conference on Earthquake Engineering, Lisbon, Portugal. 2012.

[28] J.M. Vallenas, V.V Bertero, E.P. Popov, Hysteretic behaviour of reinforced concrete structural walls. Rep. No. UCB/EERC79/20, Earthquake Engineering Research Center, Univ. of California, Berkeley, CA, 1979.

[29] I.D. Lefas, M.D. Kotsovos,N. N. Ambraseys, Behavior of reinforced concrete structural walls: strength, deformation characteristics, and failure mechanism. ACI Structural Journal, 87(1), 23-31, 1990.

[30] F.J. Vecchio, M.P. Collins, M. P, The modified compression-field theory for reinforced concrete elements subjected to shear. ACI J., 83(2), 219-231, 1986.

[31] P.S. Wong, F.J. Vecchio, H. Trommels, Vector2 \& Formworks user's manual second edition. University of Toronto, Canada, 2013.

[32] S. Popovics. A numerical approach to the complete stress-strain curve of concrete. $\mathrm{Ce}$ ment and concrete research, 3(5), 583-599, 1973.

[33] J.B. Mander, M.J.N. Priestley, R. Park, Theoretical stress-strain model for confined concrete. Journal of structural engineering, 114(8), 1804-1826, 1988.

[34] M. Seckin, Hysteretic Behavior of Cast-in-Place Exterior Beam Column SubAssemblies. PhD thesis, University of Toronto, Toronto, Canada, 1981. 
[35] Federal Emergency Management Agency, Seismic Performance Assessment of Buildings, Volume 1 - Methodology. Technical Report FEMA-P-58-1, Washington, D.C., USA, 2012.

[36] T. Paulay, M.J.N. Priestley. Seismic design of reinforced concrete and masonry buildings. Wiley, New York, 1992.

[37] Federal Emergency Management Agency, NEHRP Guidelines for Seismic Rehabilitation of Buildings. FEMA-273, Building Seismic Safety Council, Washington, D.C, 1997.

[38] S. Bianchi, J. Ciurlanti, S. Pampanin, Comparison of traditional vs low-damage structural and non-structural building systems through a cost/performance-based evaluation. Earthquake Spectra 37(1), 366-385, 2021.

[39] New Zealand Society for Earthquake Engineering, The Seismic Assessment of Existing Building - Technical Guidelines for Engineering Assessments. NZSEE 2017, New Zealand, 2017.

[40] S. Pampanin, Towards the practical implementation of performance-based assessment and retrofit strategies for RC buildings: challenges and solutions. Proceedings of the SMAR 2017, Zurich, Switzerland, September 13-15, 2017.

[41] C. Del Vecchio, R. Gentile, S. Pampanin, The simple lateral mechanism analysis (SLaMA) for the seismic performance assessment of a case study building damaged in the 2011 Christchurch earth- quake. Research report N. 2016-02, University of Canterbury, Christchurch, New Zealand, 2017

[42] S.A. Freeman, Review of the development of the capacity spectrum method. ISET J. Earthquake Technol., 41 (1), 1-13, 2004

[43] Applied technology council, Seismic evaluation and retrofit of concrete buildings. ATC 40, Redwood City, CA, USA, 1996.

[44] Ministero delle Infrastrutture, Aggiornamento delle Norme Tecniche per le Costruzioni, Suppl. ordinario $n^{\circ} 8$ alle G.U. $n^{\circ} 42$ del 20/02/2018, (in Italian) serie generale, Rome, Italy, 2018.

[45] Ministero delle Infrastrutture, Allegato A: linee guida per la classificazione del rischio sismico delle costruzioni. (in Italian). Decreto Ministeriale 65 del 07/03/2017, Rome, Italy, 2017

[46] M. Dolce, G. Manfredi G, Libro Bianco sulla ricostruzione privata fuori dai centri storici nei comuni colpiti dal sisma dell'Abruzzo del 6 Aprile 2009. (in Italian), Doppiavoce: 210. ISBN 978-88-89972-50-2, 2015.

[47] Structural Engineers Associate of California, Performance-based seismic engineering. SEAOC Vision 2000, Sacramento, California, USA, 1995.

[48] NZS1170.:5 Structural design actions part 5: earthquake actions. New Zealand, 2004

[49] D. Cardone, G. Perrone, Developing fragility curves and loss functions for masonry infill walls. Earthquakes and Structures, 9(1), 257-279, 2015.

[50] I. Nuzzo, N. Caterino, S. Pampanin, Seismic Design Framework Based on Lossperformance Matrix. Journal of Earthquake Engineering, 1-21, 2020 